\title{
Oral Carnitine Therapy in Children with Cystinosis and Renal Fanconi Syndrome
}

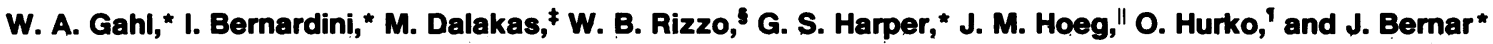 \\ *Section on Human Biochemical Genetics, Human Genetics Branch, National Institute of Child Health and Human Development, \\ National Institutes of Health, Bethesda, Maryland 20892; ${ }^{\ddagger}$ Office of the Clinical Director, National Institute of Neurological \\ and Communicative Disorders and Stroke, National Institutes of Health, Bethesda, Maryland 20892; \$Departments of Pediatrics \\ and Human Genetics, Medical College of Virginia, Richmond, Virginia 23298; "Molecular Disease Branch, \\ National Heart, Lung, and Blood Institute, National Institutes of Health, Bethesda, Maryland 20892; and 'Department of Neurology, \\ Johns Hopkins School of Medicine, Baltimore, Maryland 21205
}

\begin{abstract}
11 children with either cystinosis or Lowe's syndrome had a reduced content of plasma and muscle carnitine due to renal Fanconi syndrome. After treatment with oral L-carnitine, 100 $\mathrm{mg} / \mathrm{kg}$ per $\mathrm{d}$ divided every $6 \mathrm{~h}$, plasma carnitine concentrations became normal in all subjects within $2 \mathrm{~d}$. Initial plasma free fatty acid concentrations, inversely related to free carnitine concentrations, were reduced after 7-20 mo of carnitine therapy. Muscle lipid accumulation, which varied directly with duration of carnitine deficiency $(r=0.73)$, improved significantly in three of seven rebiopsied patients after carnitine therapy. One Lowe's syndrome patient achieved a normal muscle carnitine level after therapy. Muscle carnitine levels remained low in all cystinosis patients, even though cystinotic muscle cells in culture took up $\mathrm{L}-\left[{ }^{3} \mathrm{H}\right]$ carnitine normally. The half-life of plasma carnitine for cystinotic children given a single oral dose approximated $6.3 \mathrm{~h} ; 14 \%$ of ingested L-carnitine was excreted within $24 \mathrm{~h}$. Studies in a uremic patient with cystinosis showed that her plasma carnitine was in equilibrium with some larger compartment and may have been maintained by release of carnitine from the muscle during dialysis. Because oral L-carnitine corrects plasma carnitine deficiency, lowers plasma free fatty acid concentrations, and reverses muscle lipid accumulation in some patients, its use as therapy in renal Fanconi syndrome should be considered. However, its efficacy in restoring muscle carnitine to normal, and the optimal dosage regimen, have yet to be determined.
\end{abstract}

\section{Introduction}

Carnitine, or $\beta$-hydroxy- $\gamma$-trimethylaminobutyric acid, is a small molecule synthesized in the liver, kidney, and brain from two essential amino acids, methionine and lysine (1). Carnitine is required for the transport of long-chain fatty acids into the mitochondrial matrix, where the fatty acids are catabolized by $\beta$-oxidation in a process that produces energy for cellular metabolism $(1,2)$.

Carnitine deficiency in man can be systemic or limited to the muscle compartment. In systemic carnitine deficiency, episodes of weakness and encephalopathy can resemble those of Reye syndrome. Renal tubular reabsorption of carnitine may

Address correspondence and reprint requests to Dr. W. A. Gahl, Building 10, Room 10N-318, NICHD, National Institutes of Health, 9000 Rockville Pike, Bethesda, MD 20892.

Received for publication 9 March 1987 and in revised form 1 September 1987.

The Journal of Clinical Investigation, Inc.

Volume 81, February 1988, 549-560 be mildly impaired (3). Muscle, serum, and liver carnitine levels are all generally low in systemic carnitine deficiency (4). In contrast, only muscle carnitine levels are low in muscle carnitine deficiency. Muscle cannot synthesize carnitine, but receives its supply from the circulation, normally by a carriermediated transport system (5), This process is defective in muscle carnitine deficiency (6), which is characterized clinically by muscle weakness.

Certain types of carnitine deficiency occur because of inordinate losses of carnitine, as in disorders of organic acid metabolism (2) or in hemodialysis patients $(7,8)$. Recently, carnitine deficiency has been recognized as a concomitant of renal Fanconi syndrome $(9,10)$, a generalized transport defect in tubular reabsorption of small molecules. In Fanconi syndrome patients, free carnitine, which is normally $97 \%$ reabsorbed by renal tubules $(4,9)$, is excreted in excess amounts resulting in low plasma carnitine levels and total body carnitine depletion. Because the supply of carnitine to the muscle is impaired, muscle carnitine levels are low and a characteristic accumulation of lipid droplets develops (9), apparently reflecting deficient fatty acid oxidation.

The major identifiable cause of the renal Fanconi syndrome in children remains nephropathic cystinosis $(11,12)$, a lysosomal storage disorder due to defective lysosomal membrane transport of the amino acid cystine $(13,14)$. Cystinosis patients have plasma and muscle carnitine deficiency during the time that they have renal Fanconi syndrome, i.e., after their first year of life. By $\sim 10$ yr of age, end-stage renal disease generally leads to renal transplantation (15), which cures renal Fanconi syndrome and plasma carnitine deficiency (9).

We studied the efficacy of oral L-carnitine therapy in pretransplant patients with cystinosis. Our results suggest that L-carnitine supplementation should be considered in the treatment of children with cystinosis and renal tubular Fanconi syndrome.

\section{Methods}

Subjects. All subjects were inpatients at the National Institutes of Health Clinical Center. Except for subject No. 15, all children with nephropathic cystinosis who had not received a renal transplant were receiving chronic oral cysteamine (16), a cystine-depleting agent, under a protocol to study its efficacy in preserving renal function (17). Pretransplant cystinotic children were also receiving supplemental citrate, potassium, phosphate, and calcium as needed (11). The Lowe's (oculocerebrorenal) syndrome patients were receiving citrate and phosphate. Posttransplant cystinotic patients were taking prednisone, azathioprine, and a variety of antihypertensive medications. The 13 -yr-old cystinotic patient receiving daily peritoneal dialysis (see Figs. 6 and 7) had a serum creatinine of $12 \mathrm{mg} / \mathrm{dl}$ and had been dialyzed for the past $3 \mathrm{yr}$. Informed consent was obtained from all patients or their parents before study. 
Methods. Free and total carnitine in plasma, urine, and peritoneal fluid were assayed as previously described (9), according to a modification of the procedure of McGarry and Foster (18). Muscle carnitine was determined as described (19). Plasma free fatty acids, measured after an overnight fast (12-14 h), were determined by the method of Tserng et al. (20). Lipids were determined after an overnight fast using the Gilchem reagent system (Gilford Diagnostics, Cleveland, $\mathrm{OH}$ ). Triglyceride and cholesterol assays were performed using the enzymatic production of a formazan or quinoneimine dye, followed by absorbance measurement at $500 \mathrm{~nm}(21,22)$ and HDL cholesterol levels were determined after dextran sulfate precipitation (23). The lipoprotein cholesterol levels were then calculated as previously outlined (24). Control values are those established by the Lipid Research Clinics (25).

Open muscle biopsies were taken from the quadriceps muscle except in subject No. 23, in whom the biceps was biopsied. A needle biopsy was performed in subject No. 3. The biopsies were fresh-frozen in isopentane, cooled to $-160^{\circ} \mathrm{C}$ in liquid nitrogen, and processed for muscle histochemistry as described (26).

All the biopsy specimens, i.e., those obtained from all subjects before and after oral L-carnitine therapy, were stained with oil-red-O in two batches. Normal controls and two patient specimens were stained in both procedures, and gave similar results each time. To quantitatively compare the extent of lipid droplet accumulation in different biopsies, a lipid droplet index was determined. Biopsies were coded and scored for lipid droplets by four independent observers, who examined at least three fields for each biopsy under $40 \times$ magnification. Fields were chosen to show muscle fibers cut in cross-section rather than longitudinally. For each field, the number of fibers containing lipid droplets and the total number of fibers were determined. The ratio $(f)$ gave the percentage of fibers with lipid droplets, and provided a normalization for the fact that younger patients have smaller fibers, more fibers per field, and therefore, more fibers with lipid droplets. For the fibers with droplets, the average number of droplets per fiber $(d)$ was estimated. Each observer then assigned to each biopsy a lipid droplet index, $\mathrm{I}=(f \times d) \times 100$, a parameter which reflected both the proportion of fibers with droplets and the number of droplets per fiber. The mean coefficient of variability for a single observer examining several fields was $35 \%$; the mean coefficient of variability for a single biopsy examined by four observers was $36 \%$. The normal control index was 1.3 $\pm 0.6 \mathrm{SD}$. (See Fig. 4 for examples of stained biopsies and their lipid droplet indices.)

For in vitro carnitine uptake studies, muscle was placed into minimal Eagle's medium containing $10 \mathrm{mM}$ glutamine, $10 \%$ fetal calf serum (Gibco, Grand Island, NY), penicillin ( $100 \mathrm{U} / \mathrm{ml})$, streptomycin $(100 \mu \mathrm{g} / \mathrm{ml})$, and mycostatin $(3 \mu \mathrm{g} / \mathrm{ml})$. After dissociation by repeated enzyme digestion and physical agitation $(27,28)$, the cells were seeded and grown in $25 \mathrm{~cm}^{2}$ flasks to $60 \%$ confluence and stimulated to fuse into myotubes by the addition of $2 \%$ horse serum for $7 \mathrm{~d}$. Muscle cells from both normal and cystinotic subjects were incubated at $37^{\circ} \mathrm{C}$ in the presence of $50 \mu \mathrm{M} \mathrm{L}-\left[{ }^{3} \mathrm{H}\right]$ carnitine (Amersham Corp., Arlington Heights, IL; final specific radioactivity, $20 \mathrm{mCi} / \mathrm{mmol}$ ) with or without $1 \mathrm{mM}$ cysteamine. After $2 \mathrm{~h}$ the cells were washed twice with ice-cold phosphate buffered saline, harvested with trypsin/EDTA (Whittaker M. A. Bioproducts, Walkersville, MD) for $4 \mathrm{~min}$ at $37^{\circ} \mathrm{C}$, and collected by centrifugation at $2,000 \mathrm{~g}$ for $5 \mathrm{~min}$. The cell pellet was dissolved in 1 $\mathrm{ml}$ of $0.1 \mathrm{~N}$ sodium hydroxide and radioactivity was determined by liquid scintillation counting. An aliquot was assayed for protein using the bicinchoninic acid method (29).

Liquid L-carnitine $(100 \mathrm{mg} / \mathrm{ml})$ was a product of Sigma-Tau, Inc., Holmdel, NJ. Carnitine was administered at $100 \mathrm{mg} / \mathrm{kg}$ per $\mathrm{d}$ in divided doses given every $6 \mathrm{~h}$.

\section{Results}

Baseline parameters. 21 children with nephropathic cystinosis and renal tubular Fanconi syndrome had plasma free and total carnitine deficiency of varying degrees (Table I). Two brothers with Lowe's syndrome manifested mild carnitine deficiency. Of the 21 pretransplant cystinotic patients, 10 had normal lipoprotein profiles, 8 had type IV hyperlipoproteinemia, 2 had a type IIa pattern, and 1 had a type IIb profile. Mean total serum cholesterol, which increased in the cystinotic children as a linear function of age (data not shown), was at the upper limit of normal; an elevated VLDL cholesterol concentration accounted for most of this increase in total cholesterol. Mean serum triglyceride and plasma free fatty acid concentrations were approximately twice normal.

All seven posttransplant cystinotic patients, who no longer manifested renal Fanconi syndrome, had normal plasma carnitine levels (Table I). Serum cholesterol and triglyceride elevations persisted in these patients, but fasting free fatty acid concentrations were generally normal. The mean free fatty acid concentration was significantly less in posttransplant patients than in pretransplant patients $(P<0.001)$.

Considering all cystinosis patients, plasma free fatty acid concentrations were inversely related to plasma free carnitine concentrations (Fig. 1). The plasma free fatty acid values of two Lowe's syndrome patients with carnitine deficiency (subjects 22 and 23, Table I) were consistent with the relationship observed among the cystinotic patients (Fig. 1).

L-Carnitine therapy. One Lowe's syndrome and 11 cystinosis patients with muscle carnitine deficiency received oral L-carnitine at $100 \mathrm{mg} / \mathrm{kg}$ per d, given in divided doses every $6 \mathrm{~h}$ for up to $20 \mathrm{mo}$. All the children with cystinosis were also taking $60-89 \mathrm{mg} / \mathrm{kg}$ per $\mathrm{d}$ of oral cysteamine, a cystine-depleting free thiol $(16,17)$. Plasma concentrations of free and total carnitine, measured $5 \mathrm{~h}$ after a dose of carnitine, rose to above-normal levels within $2 \mathrm{~d}$ of the initiation of therapy, and were maintained for at least 12 mo (Fig. 2). Growth rate and mean serum VLDL cholesterol concentration did not differ before and after carnitine replacement (Table II). However, serum triglyceride concentrations increased in all patients and the mean plasma free fatty acid concentrations fell significantly with carnitine therapy in the nine children for whom paired data were available $(520 \pm 71$ vs. $334 \pm 34 \mathrm{~g} / \mathrm{ml}$, mean \pm SE, $P<0.05$ ).

Muscle carnitine deficiency was present in all patients before carnitine therapy (Table II). Muscle free carnitine values ranged from 5.2 to $11.4 \mathrm{nmol} / \mathrm{mg}$ noncollagen protein (normal, 22.7 $\pm 5.0 \mathrm{SD}, n=6$ ), and averaged $37 \%$ of normal. There was considerable fluctuation in muscle free carnitine before and after carnitine replacement, and only subjects 6 and 23 exhibited substantial free carnitine repletion in their muscles. Changes in total muscle carnitine levels, which before carnitine supplementation averaged $10.5 \pm 2.5$ (SD) nmol/mg noncollagen protein (normal, 27.9 \pm 7.7 ), mirrored the changes in free carnitine.

The number of lipid droplets seen after oil-red-O staining of each muscle biopsy was used as a gauge of the functional severity of muscle carnitine deficiency. A lipid droplet index (see Methods) was assigned to each biopsy in a blinded fashion; the higher the index, the greater was the lipid accumulation. Before carnitine therapy, the lipid droplet index, based upon a single determination in 11 different children with cystinosis, varied linearly ( $r=0.73$ ) with age (Fig. 3). Because this disorder is one in which renal Fanconi syndrome begins at a discrete age, 6-12 mo, the lipid droplet index appeared to be related to the duration of renal Fanconi syndrome and, there- 
Table I. Plasma Carnitine, Cholesterol, Triglycerides, and Free Fatty Acids of Patients with Cystinosis and Oculocerebrorenal Syndrome

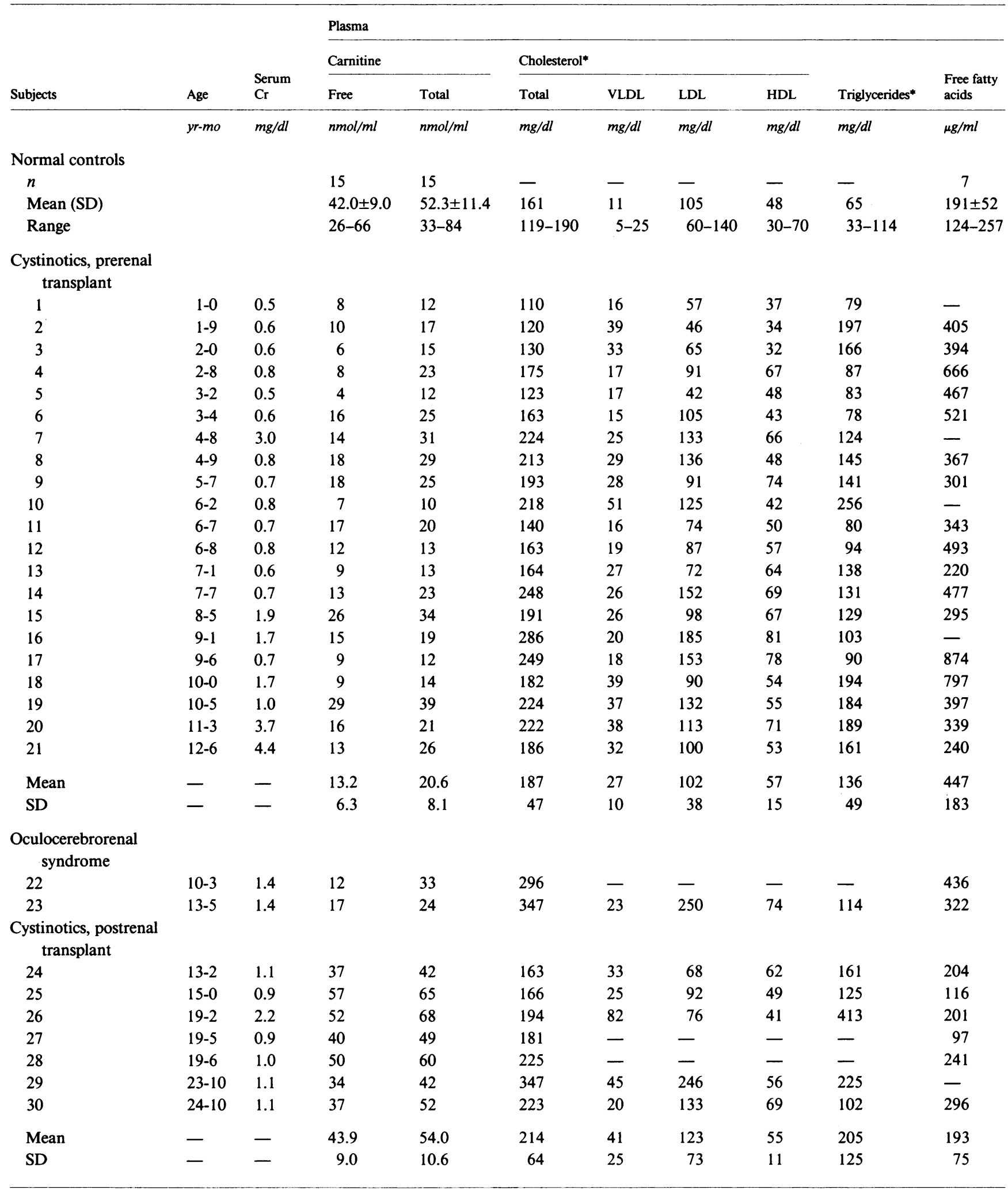

* Normal values are for 9,514 children up to 14 yr of age (25).

fore, the duration of carnitine deficiency. Photographs of representative muscle biopsies from patients of different ages demonstrated the increase in extent of lipid droplet accumulation (Fig. 4, $A-C$ ). The lipid droplet index was compared be- fore and after carnitine therapy in the seven children who underwent repeat muscle biopsies. In three patients, (No. 6, 9, and 23), the index decreased significantly; in subjects 4,8 , and 10 , it did not change significantly, and in subject 12 , it rose 


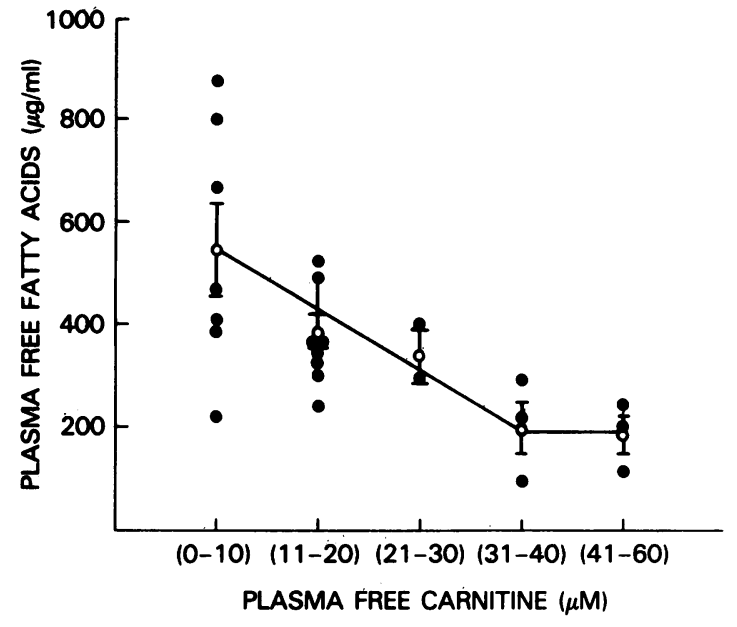

Figure 1. Relationship between plasma fasting free fatty acid concentrations and endogenous free carnitine levels in 23 cystinosis patients before carnitine therapy. Each closed circle represents one cystinotic individual not receiving carnitine replacement; patients with normal carnitine levels are postrenal transplant. For each discrete range of carnitine values (abscissa), the mean free fatty acid concentration is given by an open circle. Bars give SE. The line represents the best least-squares fit $(r=0.98)$ for the mean free fatty acid levels. For patients with normal carnitine concentrations, plasma free fatty acid levels were also normal.

markedly (Table II). For subjects 8 and 9, the amount of lipid droplets before and after carnitine replacement is illustrated by photographic comparison of simultaneously stained biopsies (Fig. 5, $A-D$ ).

Kinetic studies. To investigate the clearance of exogenously administered L-carnitine from the plasma, carnitine-deficient cystinotic patients were given a single oral dose of the compound. In three children who received $25 \mathrm{mg} / \mathrm{kg} \mathrm{L}$-carnitine, peak plasma levels of free $(31 \mu \mathrm{M})$ and total $(48 \mu \mathrm{M})$ carnitine

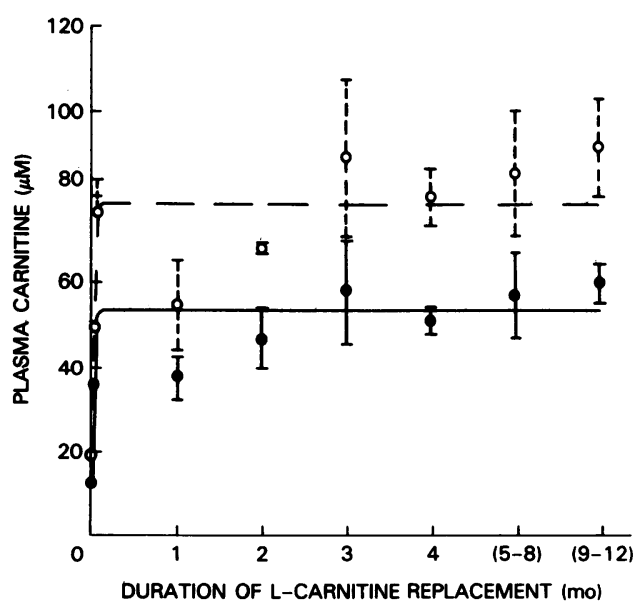

Figure 2. Plasma free and total carnitine concentrations after chronic oral L-carnitine replacement in 12 Fanconi syndrome patients. Plasma was obtained $5 \mathrm{~h}$ after a dose $(100 \mathrm{mg} / \mathrm{kg}$ per d) of L-carnitine given every $6 \mathrm{~h}$. Points represent means of at least four different patients' values for free (solid circle) and total (open circle) plasma carnitine. The 1- and 2-mo points are means of three values. Bars give SE. Above-normal plasma carnitine levels were achieved within $2 \mathrm{~d}$ of initiation of therapy. were achieved within $3 \mathrm{~h}$ (Fig. 6), and these levels fell according to first-order kinetics (data not shown). In two children who received $50 \mathrm{mg} / \mathrm{kg}$, a similar pattern was observed but with higher peak levels of free and total carnitine $(41 \mu \mathrm{M}$ and $86 \mu \mathrm{M}$, respectively). The difference in total plasma carnitine concentration between the two doses was largely a consequence of an increase in acyl, rather than free, carnitine content. For both free and total carnitine levels after either dosage, the plasma half-life for carnitine averaged $6.3 \mathrm{~h}$.

In contrast to these Fanconi syndrome patients, a 13-yr-old anuric cystinotic girl on chronic peritoneal dialysis $(10 \mathrm{~h} / \mathrm{d})$, given a single oral bolus of $50 \mathrm{mg} / \mathrm{kg} \mathrm{L}$-carnitine, displayed a higher peak plasma level of both free and total carnitine (Fig. 6). She maintained a high plasma level for at least $9 \mathrm{~h}$ after the dose. This 38.4-kg girl was not dialyzed during that period, but did undergo peritoneal dialysis for $10 \mathrm{~h}(\sim 1.9$ liters in each of five consecutive 2-h dwells), beginning $13 \mathrm{~h}$ after L-carnitine ingestion. This dialysate contained $296 \mu \mathrm{mol}$ of carnitine or $7.7 \mu \mathrm{mol} / \mathrm{kg}$ body wt. In contrast, the two Fanconi syndrome subjects (No. 3 and 13), who also received $50 \mathrm{mg} / \mathrm{kg} \mathrm{L}$-carnitine, lost 59.0 and $32.0 \mu \mathrm{mol} / \mathrm{kg}$ of total carnitine, respectively, in their urine over the same time period, indicating that the diminutions in their plasma carnitine levels resulted mainly from urinary losses (Fig. 6).

Further evidence implicating urinary loss of carnitine as the cause of carnitine deficiency was derived from measurement of the urinary carnitine excretion in chronically supplemented patients. The 11 children who received oral carnitine every $6 \mathrm{~h}$ for over 2 mo excreted 6-23\% (mean \pm SD, $14.0 \pm 5.4 \%$ ) of the ingested dose, which was $6.2-13.5 \mathrm{mmol} / \mathrm{d}$ (Table III). The average amount of carnitine excreted by these patients increased 10-fold after carnitine replacement was initiated, and the mean fractional excretion of free carnitine increased from $32.6 \pm 7.9 \%$ SE to $75.9 \pm 10.0 \%$ SE.

The high level of urinary excretion of carnitine interfered with attempts to determine whether there was equilibration between the plasma and other potential compartments in carnitine-supplemented patients. This problem was circumvented by further study of the anuric patient on peritoneal dialysis. On four separate occasions, this patient was given single oral boluses of $0,12.5,50$, and $100 \mathrm{mg} / \mathrm{kg}$ of L-carnitine just after her nightly peritoneal dialysis. $14 \mathrm{~h}$ later, her plasma carnitine was measured and the 10-h peritoneal dialysis treatment was begun. The 8-10 liter dialysate volume was assayed for total carnitine, which increased linearly with plasma total carnitine at the initiation of dialysis (Fig. 7). An equilibrium was apparently reached between the plasma and the peritoneal fluid during each 2-h pass. In addition, the total amount of dialysate carnitine was compared with the total blood content of carnitine at the start of dialysis, e.g., plasma concentration $\times$ body weight $\times 8 \%$ blood volume $\times 83 \%$ plasma (the hematocrit was $17 \%)$. The mean ratio of dialysate to total blood content of carnitine was $1.83 \pm 0.18(\mathrm{SD})(n=4)$. Because dialysis removed more carnitine from the plasma than the plasma originally contained, there must have been another larger carnitine-containing compartment in equilibrium with the plasma.

In vitro studies. Cultured muscle cells from a patient with cystinosis were studied to determine whether carnitine uptake was abnormal. Uptake of $\left[{ }^{3} \mathrm{H}\right]$ carnitine by normal muscle cells increased linearly for at least $2 \mathrm{~h}$. Fused cystinotic myotubes took up radioactive free carnitine at a normal rate when exposed to a concentration typically present in plasma $(50 \mu \mathrm{M})$ 


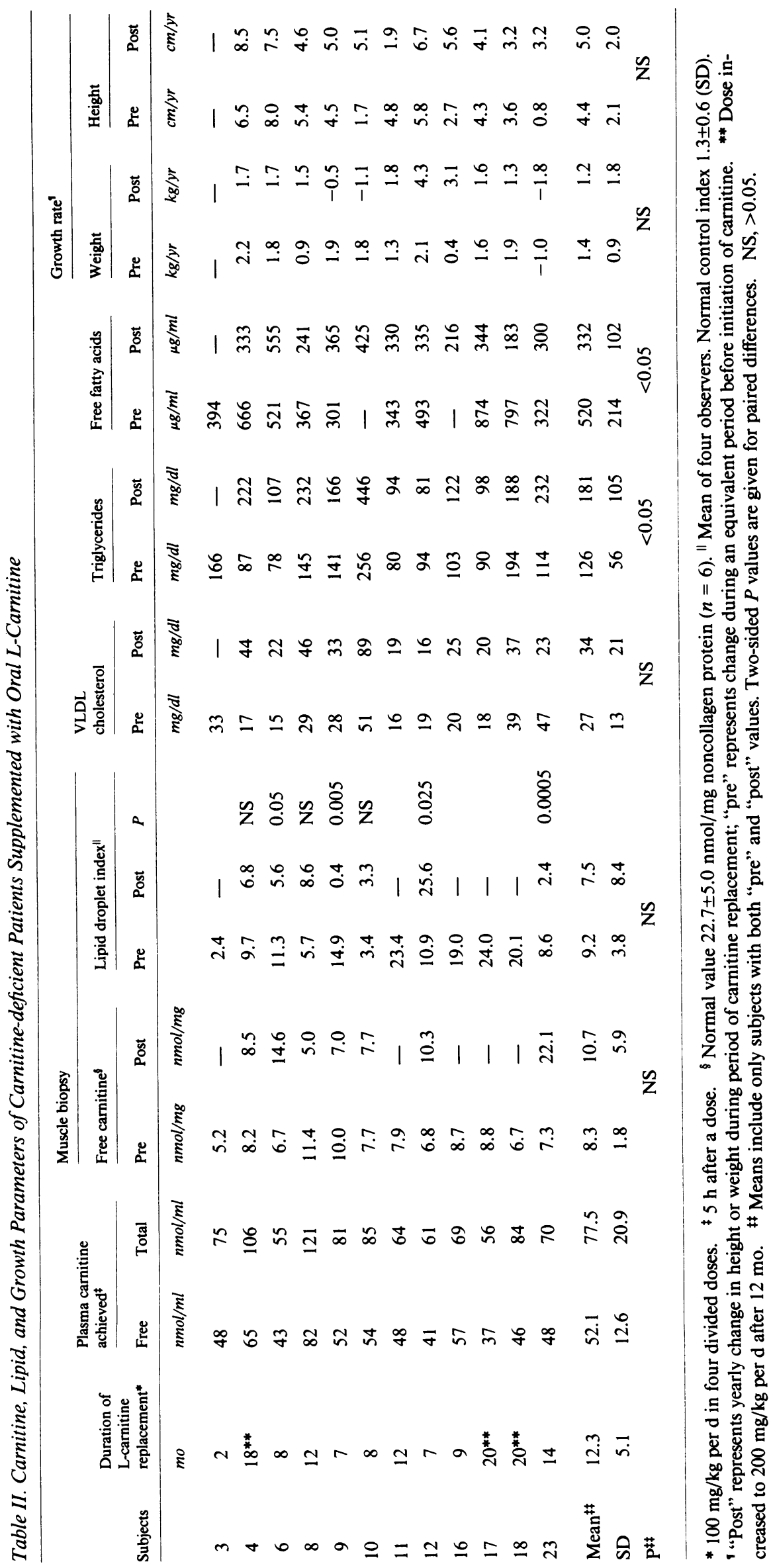




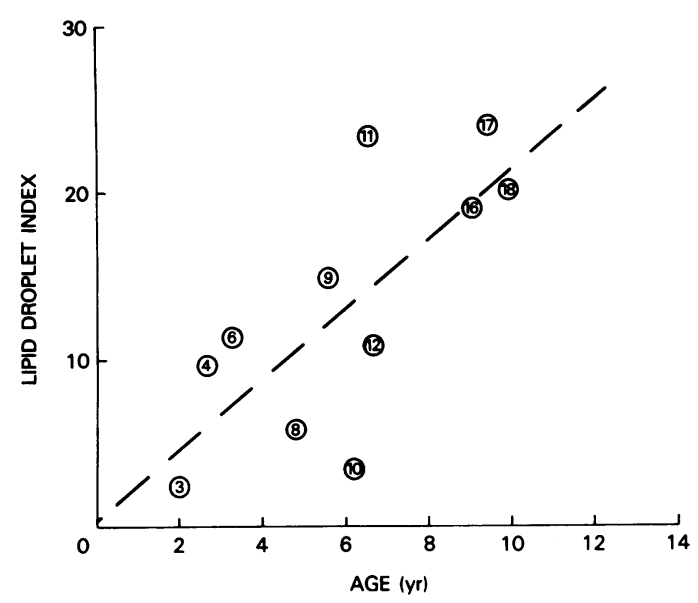

Figure 3. Muscle lipid droplet index as a function of age in 11 carnitine-deficient children with cystinosis before L-carnitine replacement. The lipid index is defined in Methods. Numbers refer to subjects listed in Table I. The linear relationship between lipid droplet index and age follows the equation $y=2.07 x+0.66(r=0.73)$.

(Table IV). In both normal and cystinotic cells, carnitine uptake proceeded at a normal rate in the presence of $1 \mathrm{mM}$ cysteamine, which is $\sim 20$ times the plasma concentration achieved in vivo by oral administration of standard doses of cysteamine in cystinotic children (30).

Clinical effects. Five of the 11 patients (No. 4, 9, 11, 12, and 23) treated with oral L-carnitine for over 2 mo had an increase in physical activity subjectively noted by their parents. For example, some children played longer and kept up better with their friends in running. Two (No. 11 and 16) had nausea and vomiting which required lowering of the carnitine dose to $60-80 \mathrm{mg} / \mathrm{kg}$ per $\mathrm{d}$. Eight of the 11 children (all except No. 4, 18, and 23) had a fishlike odor to their breath, skin, or urine, as previously described (31).

\section{Discussion}

Because children with renal tubular Fanconi syndrome manifest plasma and muscle carnitine deficiency $(9,32)$, we investigated the biochemical and clinical responses of these patients to oral carnitine therapy. Oral carnitine administration rapidly repleted plasma free and total carnitine. The peak plasma level achieved was directly related to the oral carnitine dose. Fasting plasma free fatty acid levels were inversely correlated with plasma carnitine concentrations (Fig. 1), a relationship previously reported among fasting normal subjects (33). With carnitine therapy, our deficient patients exhibited a significant decrease (520 to $332 \mu \mathrm{g} / \mathrm{ml}$ ) in their mean plasma free fatty acid concentration (Table II). A similar response has been observed in carnitine-supplemented uremic patients, whose plasma free fatty acids fell from $352 \pm 124$ (SD) mmol/liter to $255 \pm 91 \mathrm{mmol} /$ liter (34).

Carnitine supplementation did not favorably alter the serum cholesterol and triglyceride elevations in our patients. In fact, whereas the cholesterol levels were largely unchanged by treatment, serum triglycerides increased even more with carnitine therapy (Table II). Previous studies of lipid responses to carnitine replacement have largely involved hemodialysis patients. In three separate investigations $(7,8,35)$, total serum cholesterol was unchanged after normalization of plasma carnitine levels, although one study reported an increase in HDL cholesterol (7). Moreover, the serum cholesterol abnormalities in our patients would be expected to remain unchanged because postrenal transplant cystinotics, who no longer have carnitine deficiency, showed lipid abnormalities similar to pretransplant patients (Table I). Cholesterol alterations may be intrinsic to the disease cystinosis rather than to carnitine deficiency, just as cholesterol abnormalities in hemodialyzed patients appear secondary to uremia and not carnitine deficiency. Serum triglyceride levels in hemodialyzed patients have been reported to decrease $(7,8)$, remain unchanged $(36)$, or increase (35) after carnitine supplementation. It has been suggested that a rise in serum triglycerides may result from increased hepatic triglyceride synthesis due to increased availability of fatty acid substrates after carnitine repletion (35).

Although physical activity was subjectively increased in five of 11 carnitine-treated children, growth rates did not improve (Table II), and there was no ostensible increase in muscle mass. Whether these parameters will improve after longerterm carnitine repletion remains to be determined.

In most cases, carnitine therapy did not replete muscle carnitine but it did significantly decrease the accumulation of lipid droplets in three of seven subjects after 7-14 mo of supplementation. The muscle biopsies of subjects 9 and 23 returned completely to normal on carnitine therapy. Plasma carnitine deficiency probably existed in the patients with cystinosis from 1 yr of age (Table I), i.e., the onset of renal Fanconi syndrome, and muscle carnitine deficiency was present by 2 yr of age (Table II). If so, the biopsied cystinotic patients had had carnitine deficiency for 2-6 yr at the start of carnitine therapy. Their initial $60 \%$ depletion of muscle carnitine (Table II) was associated with lipid droplet accumulation, the extent of which was directly related to the duration (Fig. 3) rather than the degree (Table II) of carnitine deficiency. It was encouraging, then, that a partial or complete resolution of the lipid accumulation was observed in any of the six rebiopsied cystinotic patients, in whom muscle histology should have been worsening. The changes in the lipid droplet index were not related to staining artifacts, because all the biopsy specimens were stained simultaneously on two different occasions, and the number of droplets was counted by four independent observers each time. The worsening of the lipid accumulation in patient 12 may have been related to her diet. Her mother stated that the child had been consuming large quantities of butter and other fats, and she gained weight at a rate of 4.3 $\mathrm{kg} / \mathrm{yr}$. Her ability to catabolize free fatty acids may have been overwhelmed despite what appeared to be adequate carnitine replacement. A high-fat diet has been shown to increase carnitine clearance in humans (36) and to decrease muscle carnitine levels in rats (37).

The repeat biopsy of the biceps muscle from the Lowe's syndrome patient (No. 23) not only lost its lipid droplets, but also exhibited a return to a normal muscle carnitine level. It seems unlikely that this finding was observed merely because the biceps rather than the quadriceps was biopsied, because all muscles should have equal access to the circulation's carnitine supply. The patient had had renal Fanconi syndrome and relatively mild carnitine deficiency for an unknown period of time, with a low fractional excretion of free carnitine in the unsupplemented state (9), and a low percentage excretion of his ingested dose (Table IV). With lower renal losses, delivery 

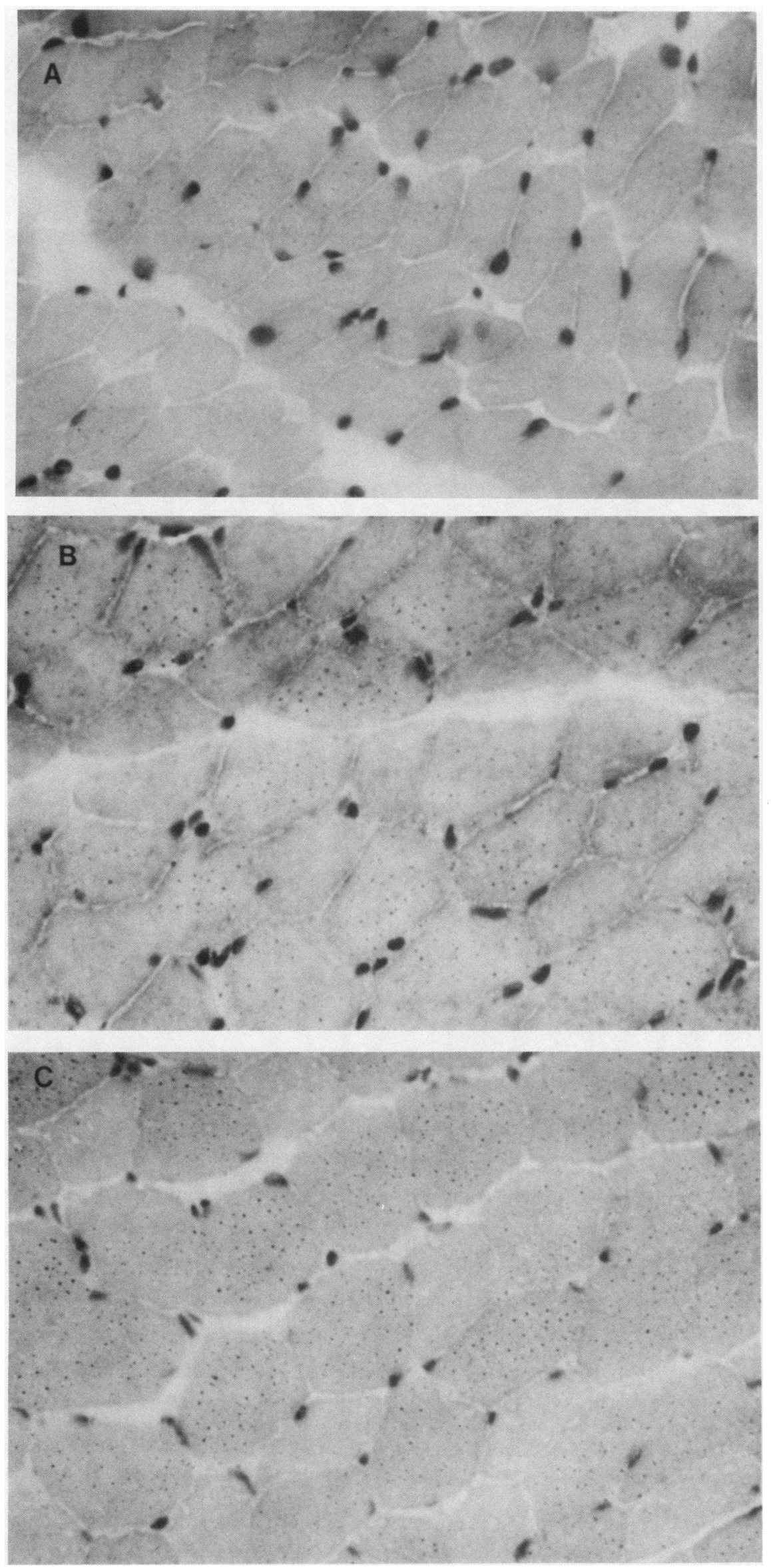

Figure 4. Transverse fresh-frozen sections of muscle biopsy specimens obtained before carnitine therapy and stained with oilred-O. The number of lipid droplets increased with age, as illustrated for patients 3 ( $A$, age 2, lipid droplet index 2.4), 12 (B age $6 \% 12$, lipid droplet index 10.9$)$, and 17 (C, age $9 \%$, lipid droplet index 24.0). All specimens were stained simultaneously and photographed at the same magnification $(400 \times)$, demonstrating the age-related increase in muscle fiber size as well. 

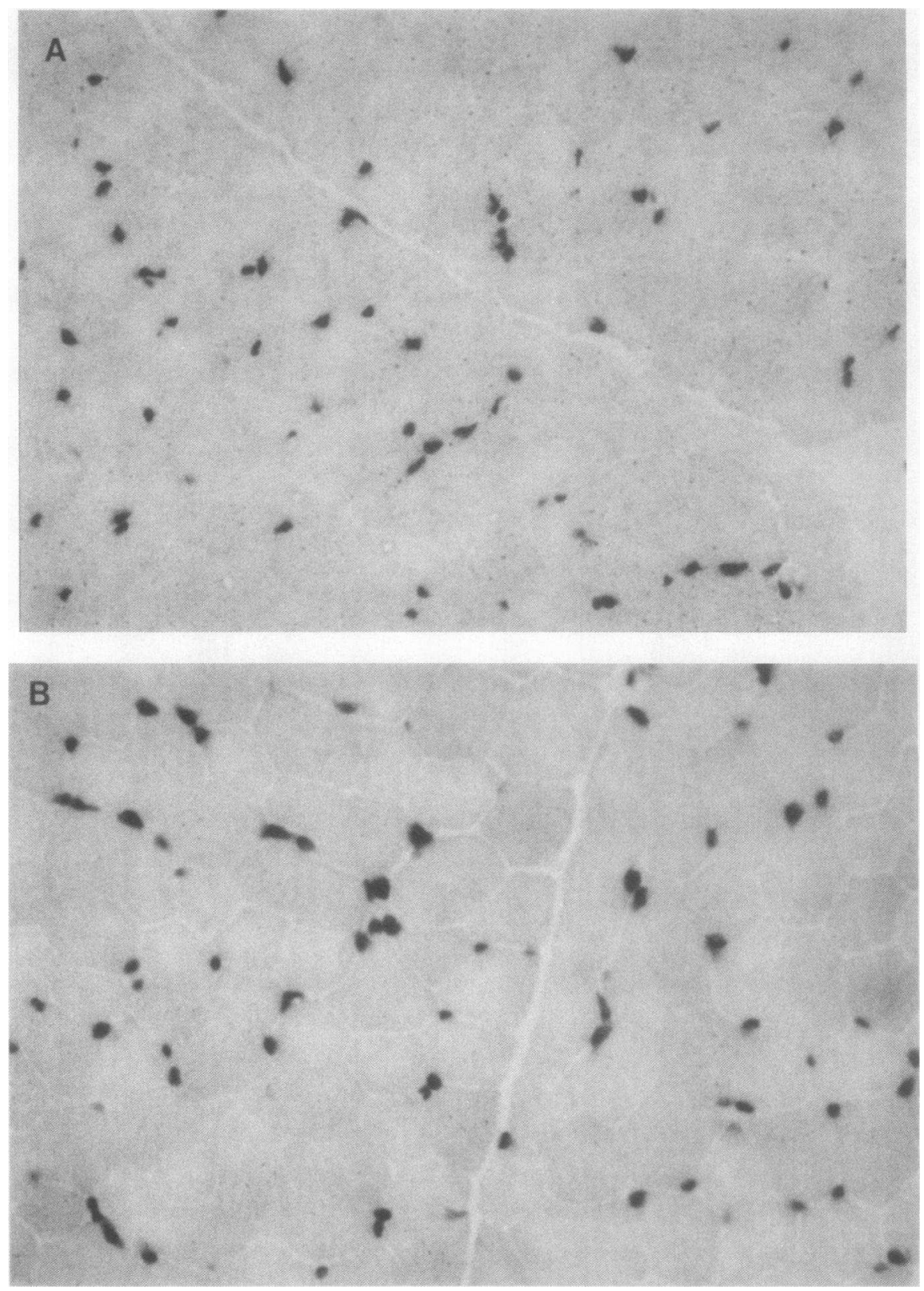

of carnitine to his muscles through the plasma may have been more effective than for the cystinotic patients. During the Lowe's syndrome patient's relatively long period of carnitine replacement, the supplemental carnitine may have first functioned biochemically to mobilize his free fatty acids and lipid droplets. Then it may have begun to replete his large muscle carnitine reservoir. In most other subjects, the second phase of muscle carnitine repletion may not have yet begun.

In other reported cases of carnitine deficiency treated with oral carnitine, muscle carnitine repletion was also variable. Hemodialysis patients with myopathic changes treated with oral L-carnitine for $\mathbf{8} \mathbf{w k}$ exhibited a restoration of their muscle carnitine levels to normal (38). A 23-yr-old woman with muscle carnitine deficiency recovered clinically after $8 \mathrm{mo}$ of DLcarnitine therapy, but her posttreatment muscle carnitine level was not reported (39). An 11-yr-old boy with systemic carnitine deficiency was treated with DL-carnitine daily for $5 \mathrm{mo}$.
Whereas plasma carnitine was normalized and the patient improved clinically, muscle carnitine remained extremely low (40). A 20-yr-old woman with systemic carnitine deficiency showed only a partial repletion of muscle total carnitine after 4 mo of oral L-carnitine supplementation (41). Another patient with a Reye syndrome-like illness became clinically normal, but muscle biopsies taken 9 and 13 mo after the start of DLcarnitine therapy revealed persistent carnitine depletion (42). Similar results were reported in a 4-yr-old girl with systemic carnitine deficiency (31). Finally, two Japanese siblings with lipid storage myopathy and hypertrophic cardiomyopathy experienced remarkable improvement in muscle strength after oral DL-carnitine. But despite normalization of plasma levels and slight improvement in muscle lipid droplet accumulation, muscle carnitine levels remained at their extremely low initial levels (43). These published experiences are consistent with our findings of partial improvement in muscle histology and 

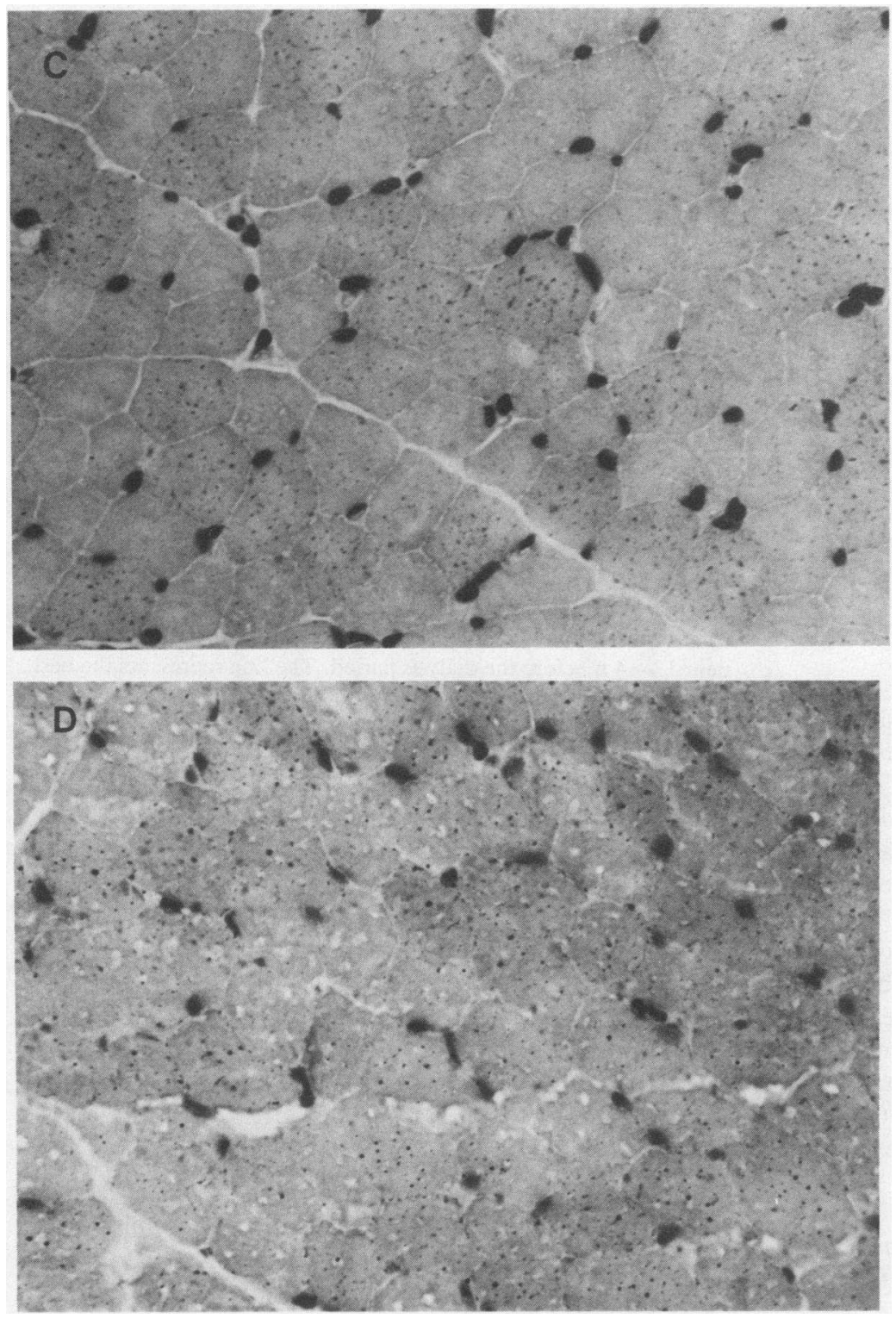

Figure 5. Transverse frozen sections of oil-red-O-stained muscle biopsies from patients $9(A$ and $B)$ and $8(C$ and $D$ ) before $(A$ and $C)$ and after $(B$ and $D)$ carnitine therapy. The lipid droplet index normalized completely in patient 9 (14.9 to 0.4$)$ after therapy but did not change substantially in patient 8 (5.7 to 8.6). All biopsies were stained simultaneously and photographed at identical magnification $(400 \times)$. Vacuoles in $(B)$ are freezing artifacts. variable muscle carnitine repletion in Fanconi syndrome patients treated with oral L-carnitine.

It is possible that the failure to eliminate lipid droplets and replete muscle carnitine in most of our treated patients was due to the effects of cysteamine on carnitine transport into muscle. However, in vitro studies showed no intrinsic defect in transport of carnitine into cystinotic muscle cells, nor did the cysteamine taken by these patients impede uptake into the muscle cells. The disulfide cystamine has been shown to inhibit carnitine uptake into other human cells (44), but only at concentrations $(0.75-1.5 \mathrm{mM})$ at least ten times the peak concentration of cysteamine ( $54 \mu \mathrm{M})$ achieved by typical oral administration of cysteamine (30). Our data on the velocity of $\left[{ }^{3} \mathrm{H}\right]$ carnitine uptake into muscle cells are in excellent agreement with those of Rebouche and Engel obtained under essentially identical experimental conditions (45). Because these in vitro studies do not exactly mimic the in vivo condition, impaired transport of carnitine from blood to muscle, whether due to cysteamine or cystinosis itself, remains a possible though unlikely impediment to muscle repletion in our patients. Alternatively, carnitine may be metabolized more rapidly in cystinotic compared with normal muscle cells.

But the most likely possibility appears to be that the enormous ongoing renal losses of carnitine suffered by renal Fanconi syndrome patients prevented muscle repletion. Whereas a patient on dialysis maintained her peak plasma carnitine level for several hours (Fig. 6) and lost $7.7 \mu \mathrm{mol}$ of carnitine $/ \mathrm{kg}$ daily in her dialysate, two cystinotic patients with Fanconi syndrome lost plasma carnitine with a halftime of $6.3 \mathrm{~h}$ and excreted in their urine 32 and $59 \mu \mathrm{mol}$ of carnitine $/ \mathrm{kg}$ daily. This degree of urinary carnitine loss resulted in the excretion of $\sim 14 \%$ of orally administered carnitine by treated patients (Table III). In comparison, 12 normal individuals given $2 \mathrm{~g}$ of oral L-carnitine had plasma carnitine half-lives approximating 


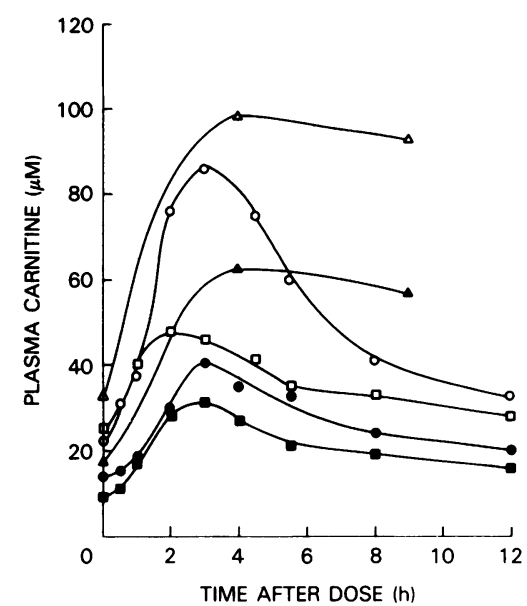

Figure 6. Plasma carnitine concentrations after a single dose of $L$ carnitine in children with cystinosis and renal Fanconi syndrome or undergoing peritoneal dialysis. Three cystinosis patients with renal Fanconi syndrome received a single oral dose of 25 $\mathrm{mg} / \mathrm{kg} \mathrm{L}$-carnitine, and plasma free ( $\bullet$ ) and total () carnitine concentrations were measured. Two cystinosis children with renal Fanconi syndrome received $50 \mathrm{mg} / \mathrm{kg}$, with determinations of free $(\bullet)$ and total (O) plasma carnitine. One girl with cystinosis and uremia, on chronic peritoneal dialysis, took $50 \mathrm{mg} / \mathrm{kg} \mathrm{L}$-carnitine and had free $(\Delta)$ and total $(\Delta)$ plasma carnitine levels measured. She was not dialyzed during the period of this study. Where applicable, each point represents the mean of two or three patients' values.

$15 \mathrm{~h}$, and excreted $7 \pm 1 \%$ of the ingested carnitine in the urine during the $24 \mathrm{~h}$ after its administration (46). The twice-normal percent excretion of ingested carnitine in the urine of Fanconi syndrome patients is especially high because these individuals had a total body depletion of carnitine and might have been expected to retain a greater percentage of ingested carnitine on that basis.

In addition, the ingested carnitine dose may be poorly absorbed in the intestine or may be rapidly degraded (6) by bacterial flora in the gut (47). Carnitine transport in the human intestine proceeds by a combination of saturable and nonsaturable processes (48), as it does in the rat (49). In that animal, the percentage of gastrointestinal absorption within $30 \mathrm{~min}$ of carnitine administration decreased with the log of the amount

Table III. Daily Urinary Excretion of Carnitine before and after Chronic Oral Carnitine Replacement in 11 Children with Renal Fanconi Syndrome

\begin{tabular}{lllll}
\hline & & \multicolumn{2}{l}{ Urinary excretion of carnitine } & \\
\cline { 3 - 4 } Subject & $\begin{array}{l}\text { L-Carnitine } \\
\text { dosage }\end{array}$ & $\begin{array}{l}\text { Before } \\
\text { replacement }\end{array}$ & $\begin{array}{l}\text { After } \\
\text { replacement }\end{array}$ & $\begin{array}{l}\text { Excretion of } \\
\text { replacement } \\
\text { dosage }\end{array}$ \\
\hline & $m m o l / d$ & $m m o l / d$ & $m m o l / d$ & $\%$ \\
4 & 6.2 & 0.07 & 1.07 & 17.3 \\
6 & 7.4 & 0.08 & 1.12 & 15.1 \\
8 & 8.7 & 0.14 & 2.01 & 23.1 \\
9 & 9.9 & 0.10 & 1.25 & 12.6 \\
10 & 9.9 & 0.03 & 1.25 & 12.6 \\
11 & 11.7 & 0.17 & 2.44 & 20.9 \\
12 & 11.2 & 0.20 & 2.03 & 18.1 \\
16 & 9.4 & 0.15 & 0.81 & 8.6 \\
17 & 11.2 & 0.17 & 0.66 & 5.9 \\
18 & 13.6 & 0.08 & 1.39 & 10.2 \\
23 & 18.6 & 0.19 & 1.69 & 9.1 \\
Mean \pm SD & & $0.13 \pm 0.06$ & $1.43 \pm 0.55$ & $14.0 \pm 5.4$ \\
\hline
\end{tabular}

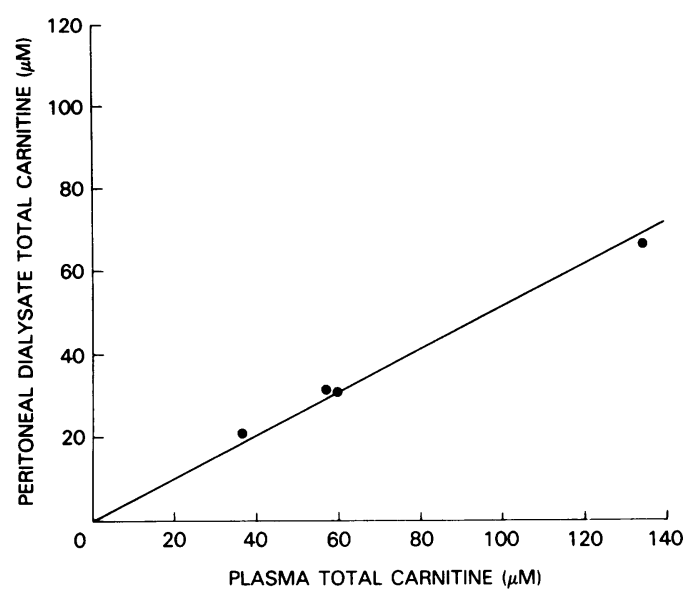

Figure 7. Relationship between carnitine concentrations in plasma and peritoneal dialysate in a 13-yr-old girl with cystinosis. The 38.4$\mathrm{kg}$ patient received peritoneal dialysis for $10 \mathrm{~h}$ on four separate occasions. Her plasma total carnitine was measured just before dialysis, and the carnitine concentration in the 8-10-liter dialysate was also assayed. Different concentrations of plasma carnitine were achieved by administering $0,0.5,2.0$, or $4.0 \mathrm{~g}$ of $\mathrm{L}$-carnitine orally to the patient 13-14 $\mathrm{h}$ before the dialysis period. The line represents the best least-squares fit for the data $(r=1.00)$.

of intraluminal carnitine given. The percentage absorption was $80 \%$ at $1-10 \mathrm{nmol} \mathrm{L}$-carnitine but only $5 \%$ at $0.1-1 \mathrm{mmol}$ (50). A typical $10-\mathrm{kg}$ cystinotic child would receive $1.5 \mathrm{mmol}$ L-carnitine per dose. If we assume similar kinetics of absorption in humans and rats, total intestinal absorption of carnitine in our patients, even considering the larger volume of their intestinal lumens, could approximate only $15-20 \%$. If so, then the difference between losing 7\% of an ingested dose in the urine (46) and losing 14\% (Table III) becomes substantial. In fact, it may represent an eightfold difference in amount of ingested carnitine retained between normal individuals ( 15 $-7=8 \%)$ and Fanconi syndrome patients $(15-14=1 \%)$. This could seriously hamper attempts to replete the muscle compartment, whose deficit amounts to several millimoles of carnitine in our patients.

Another factor may contribute to the failure to replete muscle carnitine in Fanconi syndrome patients. Evidence suggests that tissue, plasma, and dialysis fluid carnitine levels are in equilibrium (Fig. 7), and that carnitine can be actively re-

Table IV. Cysteamine Effects on Carnitine Uptake by Normal and Cystinotic Myotubes in Culture

\begin{tabular}{ll}
\hline Myotube culture & Carnitine uptake \\
\hline & nmol/mg protein per $h$ \\
Normal control & 0.17 \\
+ cysteamine $(1 \mathrm{mM})$ & 0.14 \\
Cystinotic control & 0.24 \\
+ cysteamine $(1 \mathrm{mM})$ & 0.23
\end{tabular}

Normal and cystinotic (subject No. 9) myotubes were exposed to 50 $\mu \mathrm{M}\left[\mathrm{L}-{ }^{3} \mathrm{H}\right]$ carnitine in the presence or absence of $1 \mathrm{mM}$ cysteamine. After $2 \mathrm{~h}$ at $37^{\circ} \mathrm{C}$, the cells were washed and carnitine uptake measured. Results are means of duplicate determinations. 
leased from tissue stores into the plasma pool during dialysis $(51,52)$. This suggests that, in patients losing plasma carnitine rapidly through the kidneys, carnitine may be released from muscle to achieve a normal plasma level, as proposed by Rebouche and Engel (6). If so, then the normal plasma levels seen in our carnitine-treated patients reflect a process of supplying muscle at some times but draining muscle at others. Under these circumstances, one might expect it to be difficult to restore to normal a large carnitine compartment, i.e., the muscle which contains $92-97 \%$ of whole-body carnitine stores (6), through a constantly leaking small-bore spiggot, the bloodstream.

We conclude that oral L-carnitine therapy in Fanconi syndrome patients increased plasma carnitine levels and cleared free fatty acids from the plasma. However, the resolution of muscle lipid droplets and the restoration of muscle carnitine levels to normal has not been demonstrated in the majority of cases. A long-term trial of oral carnitine therapy, administered at increased dosages and frequencies, is required to determine whether such a favorable outcome can be achieved.

\section{Acknowledgments}

We appreciate the efforts of the $9 \mathrm{~W}$ nursing staff at the National Institutes of Health Clinical Center, and the excellent secretarial assistance of Colleen Genovese.

\section{References}

1. Broquist, H. P. 1982. Carnitine biosynthesis and function. Fed. Proc. 41:2840-2842.

2. Engel, A. G., and C. J. Rebouche. 1984. Carnitine metabolism and inborn errors. J. Inherited Metab. Dis. 7(Suppl. 1):38-43.

3. Engel, A. G., C. J. Rebouche, D. M. Wilson, A. M. Glasgow, C. A. Romsche, and R. P. Crose. 1981. Primary systemic carnitine deficiency. II. Renal handling of carnitine. Neurology. 31:819-825.

4. Rebouche, C. J., and A. G. Engel. 1983. Carnitine metabolism and deficiency syndromes. Mayo Clin. Proc. 58:533-540.

5. Tubbs, P. K., R. R. Ramsay, and M. R. Edwards. 1980. Inhibitors of carnitine transport and metabolism. In Carnitine Biosynthesis, Metabolism, and Functions. R. A. Frankel and J. D. McGarry, editors. Academic Press, New York. 207-218.

6. Rebouche, C. J., and A. G. Engel. 1984. Kinetic compartmental analysis of carnitine metabolism in the human carnitine deficiency syndromes. Evidence for alterations in tissue carnitine transport. $J$. Clin. Invest. 73:857-867.

7. Lacour, B., J. Chanard, M. Haguet, C. Basile, R. Assan, S. Di Giolio, C. Ciancioni, B. Lebkiri, T. Drueke, and J. L. Funck-Bretano. 1980. Carnitine improves lipid anomalies in haemodialysis patients. Lancet. ii:763-764.

8. Guarnieri, G. F., F. Ranieri, G. Toigo, A. Vasile, M. Ciman, V. Rizzoli, M. Moracchiello, and L. Campanacci. 1980. Lipid-lowering effect of carnitine in chronically uremic patients treated with maintenance hemodialysis. Am. J. Clin. Nutr. 33:1489-1492.

9. Bernardini, I., W. B. Rizzo, M. Dalakas, J. Bernar, and W. A. Gahl. 1985. Plasma and muscle free carnitine deficiency due to renal Fanconi syndrome. J. Clin. Invest. 75:1124-1130.

10. Steinman, B., C. Bachmann, J.-P. Colombo, and R. Gitzelmann. 1987. The renal handling of carnitine in patients with selective tubulopathy and with Fanconi syndrome. Pediatr. Res. 21:201-204.

11. Gahl, W. A. 1986. Cystinosis coming of age. Adv. Pediatr. 33:95-126.

12. Schneider, J. A., and J. D. Schulman. 1983. Cystinosis. In The Metabolic Basis of Inherited Disease. 5th ed. J. B. Stanbury, J. B. Wyngaarden, D. S. Fredrickson, J. L. Goldstein, and M. S. Brown, editors. McGraw-Hill, New York. 1844-1866.
13. Gahl, W. A., N. Bashan, F. Tietze, I. Bernardini, and J. D. Schulman. 1982. Cystine transport is defective in isolated leukocyte lysosomes from patients with cystinosis. Science (Wash. DC). 217:1263-1265.

14. Gahl, W. A., F. Tietze, N. Bashan, I. Bernardini, D. Raiford, and J. D. Schulman. 1983. Characteristics of cystine counter-transport in normal and cystinotic lysosome-rich leucocyte granular fractions. Biochem. J. 216:393-400.

15. Gretz, N., F. Manz, R. Augustin, et al. 1982. Survival time in cystinosis: a collaborative study. Proc. Eur. Dial. Transplant Assoc. 19:582-589.

16. Thoene, J. G., R. G. Oshima, J. C. Crawhall, D. L. Olson, and J. A. Schneider. 1976. Intracellular cystine depletion by aminothiols in vitro and in vivo. J. Clin. Invest. 58:180-189.

17. Gahl, W. A., G. F. Reed, J. G. Thoene, J. D. Schulman, W. B. Rizzo, A. J. Jonas, D. W. Denman, J. J. Schlesselman, and J. A. Schneider. 1987. Cysteamine therapy for children with nephropathic cystinosis. $N$. Engl. J. Med. 316:971-977.

18. McGarry, J. D., and D. W. Foster. 1976. An improved and simplified radioisotopic assay for the determination of free and esterified carnitine. J. Lipid Res. 17:277-281.

19. Cederblad, G., S. Lindstedt, and K. Lundholm. 1974. Concentration of carnitine in human muscle tissue. Clin. Chim. Acta. 53:311-321.

20. Tserng, K.-Y., R. M. Kliegman, E.-L. Miettinen, and S. C. Kalhan. 1981. A rapid, simple, and sensitive procedure for the determination of free fatty acids in plasma using glass capillary column gas-liquid chromatography. J. Lipid Res. 22:852-858.

21. Gilford Diagnostics. 1980. Gilchem single vial reagent method for triglyceride. In Gilford System Instruction Manual. 4111-5:1-8.

22. Gilford Diagnostics. 1981. Gilchem single vial reagent method for cholesterol. In Gilford System Instruction Manual. 49119-3:108.

23. Warnick, G. R., J. Benderson, J. J. Albers, E. E. Baillie, B. Sexton, E. J. Schaefer, D. Carlson, M. Hill, H. B. Brewer, Jr., D. A. Wiebe, J. Hazelhurst, and G. R. Cooper. 1982. Dextran sulfate-Mg ${ }^{2+}$ precipitation procedure for quantitation of high density-lipoprotein cholesterol. Clin. Chem. 28:1379-1388.

24. Hoeg, J. M., E. J. Schaefer, C. A. Romano, E. Bou, A. Pikus, L. A. Zech, K. R. Bailey, R. F. Gregg, P. W. F. Wilson, D. L. Sprecher, A. M. Grimes, N. G. Sebring, E. J. Ayres, C. E. Jahn, and H. B. Brewer, Jr. 1984. Neomycin and plasma lipoproteins in type II hyperlipoproteinemia. Clin. Pharmacol. Ther. 36:555-565.

25. Lipid Research Clinics Population Study Book. 1980. The Prevalence Study. Vol. 1. National Institutes of Health Publication No. 8-1527.

26. Engel, W. K. 1970. Selective and nonselective susceptibility of muscle fiber types: a new approach to human neuromuscular diseases. Arch. Neurol. 22:97-117.

27. Wilson, S. H., B. K. Schrier, J. L. Farber, E. J. Thompson, R. H. Rosenberg, A. J. Blume, and M. W. Niremberg. 1972. Markers for gene expression in cultured cells from the nervous system. J. Biol. Chem. 247:3159-3169.

28. Yasin, R., G. Van Veers, K. C. E. Nurse, S. Al-Ani, D. N. Landon, and E. J. Thompson. 1977. A quantitative technique for growing human adult skeletal muscle in culture starting from mononucleated cells. J. Neurol. Sci. 32:347-60.

29. Smith, P. K., R. I. Krohn, G. T. Hermanson, A. K. Mallia, F. H. Gartner, M. D. Provenzano, E. K. Fujimoto, N. M. Goeke, B. J. Olson, and D. C. Klenk. 1985. Measurement of protein using bicinchoninic acid. Anal. Biochem. 150:76-85.

30. Jonas, A. J., and J. A. Schneider. 1982. Plasma cysteamine concentration in children treated for cystinosis. J. Pediatr. 100:321323.

31. Petrykowski, W. V., U.-P. Ketelsen, E. Schmidt-Somnerfeld, D. Penn, E. Sawicka, E. Struck, W. Lehnert, K. Happ, and H.-M. Strassburg. 1985. Primary systemic carnitine deficiency under successful therapy: clinical, biochemical, ultrahistochemical and renal clearance studies. Clin. Neuropathol. 4:63-71. 
32. Steinmann, B., C. Bachmann, J.-P. Colombo, and R. Gitzelmann. 1987. The renal handling of carnitine in patients with selective tubulopathy and with Fanconi syndrome. Pediatr. Res. 21:201-204.

33. Frohlich, J., D. W. Seccombe, P. Hahn, P. Dodek, and I. Hynie. 1978. Effect of fasting on free and esterified carnitine levels in human serum and urine: correlation with serum levels of free fatty acids and $\beta$-hydroxybutyrate. Metabolism. 27:555-561.

34. Bougneres, P. F., B. Lacour, S. DiGiulio, and R. Assan. 1979. Hypolipaemic effect of carnitine in uraemic patients. Lancet. i:14011402.

35. Weschler, A., M. Aviram, M. Levin, D. S. Better, and J. G. Brook. 1984. High dose of L-carnitine increases platelet aggregation and plasma triglyceride levels in uremic patients on hemodialysis. Nephron. 38:120-124.

36. Cederblad, G. 1987. Effect of diet on plasma carnitine levels and urinary carnitine excretion in humans. Am. J. Clin. Nutr. 45:725729.

37. Tsai, A. C., D. R. Romsos, and G. A. Leveille. 1974. Significance of dietary carnitine for growth and carnitine turnover in rats. $J$. Nutr. 104:782-792.

38. Bellinghieri, G., V. Savica, A. Mallamance, C. DiStefano, F. Consolo, L. G. Spagnoli, S. Villashi, G. Palmieri, M. Corsi, and T. Maccari. 1983. Correlation between increased serum and tissue L-carnitine levels and improved muscle symptoms in hemodialyzed patients. Am. J. Clin. Nutr. 38:523-531.

39. Prockop, L. D., W. K. Engel, and A. Shug. 1983. Nearly fatal muscle carnitine deficiency with full recovery after replacement therapy. Neurology. 33:1629-1631.

40. Karpati, G., S. Carpenter, A. G. Engel, G. Watters, J. Allen, S. Rothman, G. Klassen, and O. A. Mamer. 1975. The syndrome of systemic carnitine deficiency. Clinical, morphologic, biochemical, and pathophysiologic features. Neurology. 25:16-24.

41. Di Donato, S., D. Pelucchetti, M. Rimoldi, M. Mora, B. Garavaglia, and G. Finocchiaro. 1984. Systemic carnitine deficiency: clinical, biochemical, and morphological cure with L-carnitine. Neurology. 34:157-162.
42. Duran, M., J. B. C. de Klerk, S. K. Wadman, H. R. Scholte, R. P. Beekman, and F. G. I. Jennekens. 1984. Systemic carnitine deficiency: benefit of oral carnitine supplements vs. persisting biochemical abnormalities. Eur. J. Pediatr. 142:224-228.

43. Matsuishi, T., K. Hirata, K. Terasawa, H. Kato, M. Yoshino, E. Ohtaki, F. Hirose, I. Nonaka, N. Sugiyama, and K. Ohta. 1985. Successful carnitine treatment in two siblings having lipid storage myopathy with hypertrophic cardiomyopathy. Neuropediatrics. 16:6-12.

44. Kjernes, V., and P. Molstad. 1981. The effect of sulfhydryl blocking agents on the uptake of L-carnitine in an established human cell line (CCL 27). Scand. J. Clin. Lab. Invest. 41:209-213.

45. Rebouche, C. J., and A. G. Engel. 1982. Carnitine transport in cultured muscle cells and stem fibroblasts from patients with primary systemic carnitine deficiency. In Vitro (Rockville). 18:495-500.

46. Bach, A. C., H. Schirardin, M.-O. Sihr, and D. Storck. 1983. Free and total carnitine in human serum after oral ingestion of L-carnitine. Diabete \& Metab. 9:121-124.

47. Rebouche, C. J., D. L. Mack, and P. F. Edmonson. 1984. L-Carnitine dissimilation in the gastrointestinal tract of the rat. Biochemistry. 23:6422-6426.

48. Hamilton, J. W., B. U. Li, A. L. Shug, and W. A. Olson. 1986. Carnitine transport in human intestinal biopsy specimens. Demonstration of an active transport system. Gastroenterology. 91:10-16.

49. Gudjonsson, H., B. U. Li, A. L. Shug, and W. A. Olson. 1985. In vivo studies of intestinal carnitine absorption in rats. Gastroenterology. 88:1880-1887.

50. Gross, C. J., and L. M. Henderson. 1984. Absorption of D- and L-carnitine by the intestine and kidney tubule in the rat. Biochim. Biophys. Acta. 772:209-219.

51. Moorthy, A. V., M. Rosenblum, R. Rajaram, and A. L. Shug. 1983. A comparison of plasma and muscle carnitine levels in patients on peritoneal or hemodialysis for chronic renal failure. Am. J. Nephrol. 3:205-208.

52. Panzetta, G., G. Bonadonna, P. Giovene, and D. DeGrandis. 1985. Carnitine kinetics during dialysis. Evidence of unilateral transport from tissues to plasma. Nephron. 41:230-234. 